\title{
Testing a Unified Model of Task-specific Motivation: How teachers appraise three professional development activities
}

\author{
Cornelis J. de Brabander ${ }^{a, b, c} \&$ Folke J. Glastra ${ }^{a}$ \\ ${ }^{a}$ Department of Educational Studies, Leiden University, The Netherlands \\ ${ }^{\text {b }}$ Query Informatisering, Voorhout, The Netherlands \\ ${ }^{c}$ Welten Institute, Open University of the Netherlands
}

Article received 1 January / revised 20 February / accepted 20 February / available online June 21

\begin{abstract}
This article tests the tenability of a Unified Model of Task-specific Motivation (UMTM). The UMTM integrates task-specific components from several theories of motivation. Core of the model are four interacting but relatively independent types of valences. Affective and cognitive valences represent feelings while doing an activity and thoughts about the value of its consequences respectively; both affective and cognitive valences can be positive and negative, hence calling for approach and avoidance motivation respectively. The interaction between these four types of valences results in a valence appraisal that influences readiness for action. Task-specific antecedents, autonomy, feasibility, social relatedness and subjective norm, influence valences. 441 Primary school teachers provided judgments of all components of the model except social relatedness for three imaginary professional learning activities. The three activities were framed as a school board decided, a team decided and a personally decided learning activity. Structural equation modelling showed that for each activity a separate model was needed. How valences influenced readiness for action was specific to each activity. In the board and team decided activities, for instance, readiness for action appeared to be based predominantly on cognitive valences, while in the personally decided activity affective and cognitive valences showed a more balanced contribution. Regarding task-specific antecedents, however, the picture was less clear. Nevertheless, the UMTM proved to offer rich possibilities for the explanation of complex motivational phenomena and promises a significant reduction of the superabundance of theories that encumbers motivation research.
\end{abstract}

Keywords: motivation; intrinsic motivation; extrinsic motivation; subjective task value; professional development 


\section{Introduction}

This article explores the structural relations between the components of a Unified Model of Taskspecific Motivation (UMTM). In order to allow this exploration we collected appraisals from primary school teachers about imaginary professional learning activities. In the field of educational psychology, and not only there, we may notice a vast proliferation of theories of motivation (Boekaerts, van Nuland, \& Martens, 2010; Schunk, Pintrich, \& Meece, 2008). These theories appear to conflict in different ways. The UMTM (Figure 1) is an attempt to integrate existing theories on task-specific motivation and is explained in depth by De Brabander \& Martens (2014).

The UMTM focuses on task-specific aspects of motivation, that is, motivation for rather specific action options that are open to the actor. The model does not refer to motivation for broad fields of action like sports or mathematics, but is applicable to rather specific acts like reading job relevant books or papers. Furthermore, the model focuses on motivation and consequently disregards actual action or the feedback loops from actual action. Its intention is to provide a picture of the components that are necessary to describe the motivation of a person for a specific activity at a specific point in time.

The constituent parts of the model stemmed from or were suggested by several motivation theories, like the self-determination theory (Deci \& Ryan, 2000; Ryan \& Deci, 2000a, 2000b), the flow theory of Csikszentmihalyi (1990), the person-object theory of interest proposed by Krapp (2002; 2005), and several expectancy*value theories, namely the social-cognitive theory of Bandura $(1977 ; 1986 ; 1992 ; 1997 ; 2001$; Schunk \& Pajares, 2010), the expectancy*value theory of achievement motivation (Wigfield \& Eccles, 2000) and the theory of planned behavior of Ajzen and Fishbein (Ajzen, 1991; Ajzen \& Fishbein, 2008). The reasons for the selection of these theories and the exclusion of others are clarified by De Brabander and Martens (2014).

\section{The Unified Model of Task-specific Motivation}

For a full explanation of the Unified Model of Task-specific Motivation we refer to De Brabander and Martens (2014). The account of the model given here is a slightly adapted version. By and large, however, the analysis and arguments of the original authors still apply.

\subsection{Affective and cognitive valences}

Motivation is defined as readiness for action. It is a certain level of willingness to do an activity. Readiness for action is influenced by a valence appraisal in which affective and cognitive valences are combined on a common scale. The valence appraisal represents the overall attractiveness of an activity. Affective and cognitive valences are produced by separate and relatively independent systems of behaviour regulation. Affective valences are produced by an affective system of behaviour regulation; cognitive valences are produced by a cognitive behavioural regulation system (Krapp, 2002, 2005; Epstein, 1994). Affective valences are defined as feelings that originate from undertaking an activity (cf. self-determination theory, flow theory). Affective valences represent the levels of positive and negative feelings one experiences when doing an activity. They emanate from an automatic (unavoidable) and mechanical, that is unintentional, response to an action 'object' the person apperceives. Any action that comes to mind as an action option immediately brings about feelings about that action. The important characteristic of affective valences is not that they have no reason or function, but that their reason or function is not necessarily known and often is not known. Cognitive valences are defined as the articulation and valuation of consequences of performing an activity (cf. expectancy*value theories). Cognitive valences are explicit and brought about by active reflection of the prospective actor. Any activity has multiple consequences, intended and unintended, each of which will have a separate cognitive valence. The quality of cognitive valences obviously depends on the actor's competence to articulate and value consequences of an activity. 


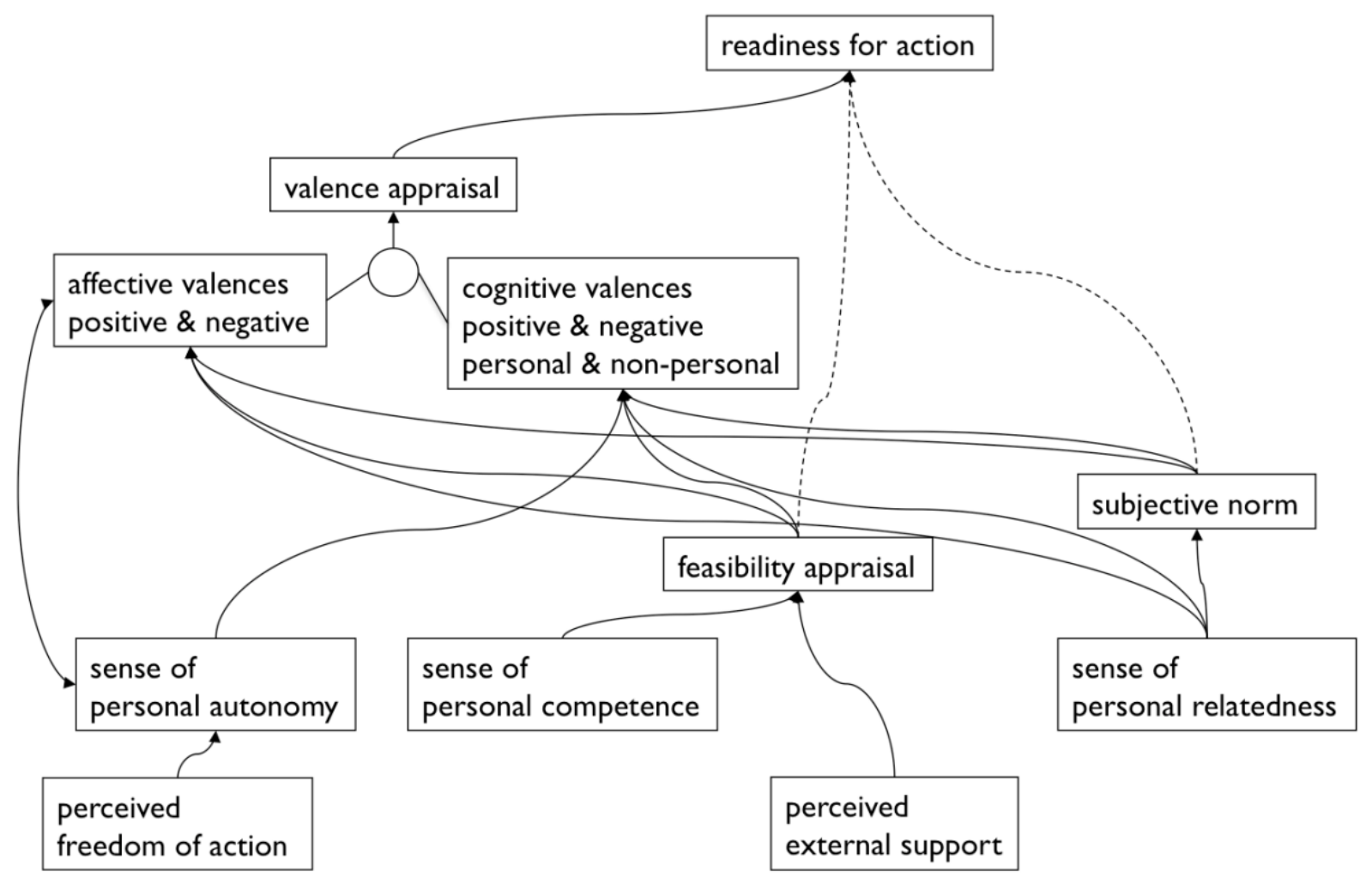

Figure 1. A Unified Model of Task-specific Motivation. Adapted from De Brabander \& Martens (2014).

Cognitive valences can be broken up in different parts depending on who acquires the cognized outcome value. Evidently, the first one that profits from an activity is always the acting person himself or herself. What other components of cognitive valence need to be distinguished depends on the specific context. In the context of education with teachers as actors, the student and the school as an institution are natural candidates. In other contexts these non-personal parts of cognitive valences will have different labels. Affective valences may also have different parts, because some parts or aspects of an activity may be pleasurable, while others may be less pleasurable or even unpleasurable, but affective valences have no non-personal component. Relevant are only the feelings that the person self experiences about an activity. Feelings of other persons (as attributed by the actor) can only enter the motivational play in the form of non-personal cognitive valences.

An important field of conflict between different motivation theories is the relation between affective and cognitive valences. In self-determination theory affective and cognitive valence are oppositional endpoints on a single dimension: from completely extrinsic to completely intrinsic. Expectancy*value theories blur the conceptual distinction and regard both types as additive: intrinsic value is just another type of subjective value. The UMTM follows Krapp $(2002$, 2005) by defining affective valences and cognitive valences as two theoretically independent categories of motives that emanate from two interacting, but distinct systems of behaviour regulation. What is pleasurable to do, in general is also recognized as profitable and vice versa, but discrepancies between the two are also possible ('I know it is good for me, but I absolutely don't feel like it' or 'I have not the faintest idea what it is good for, but it certainly is fun to do) and it is the merit of selfdetermination theory to have demonstrated the possible adverse effects of such discrepancies in educational 
contexts on performance quality, self-esteem, and general well-being (Ryan \& Deci, 2000a). This view of affective and cognitive valences as discrete but related implies that they are sometimes additive and sometimes opposed, and that readiness for action consequentially depends on the specific configuration of all valences involved.

\subsection{Positive and negative valences}

The distinction between affective and cognitive valences is combined with the distinction between approach and avoidance motivation (Elliot, 2006; Elliot \& Church, 1997). This distinction is related to the possibility of valences to be positive or negative. Positive valences call for an action that promises to realize them. Negative valences call for refraining from an action or for initializing a counteraction in order to prevent their realization. Thus, the quantity of valences is not one-dimensional, but needs to be split up in two relatively independent dimensions: positive valences, running from neutral to highly positive, and negative valences, running from neutral to highly negative.

Combining the distinction between positive and negative valences with the distinction between affective and cognitive valences allows for four relatively independent motivational components. Affective and cognitive valences, both consisting of positive and negative valences, combine in a resultant value, which we call valence appraisal, which in turn determines readiness for action. Such a conception is very much compatible with the notion of multiple consequences (including costs!) combining into the cognitive valence of a course of action. Affective valences also comprise multiple aspects, some of which are pleasurable whereas others may be unpleasurable. This fourfold conceptualization promises to provide more and better possibilities for the explanation of complex motivational phenomena.

\subsection{Task-specific antecedents}

The UMTM identifies autonomy, feasibility, relatedness, and, adopted from the theory of planned behaviour, subjective norm as important task-specific antecedents of valences. Autonomy refers to the origin of the action: the self or an internal or external source that is experienced as foreign. Feasibility - that replaces the concept of competence for reasons that will become clear below - concerns the question whether it is possible to complete an activity successfully. Relatedness refers to the level of belongingness between the people that participate in the action context. Subjective norm entails the inclination to abide by the task-related norms of others in the action context. There is a multitude of possible relations between these antecedents and action valences, but for the moment, it is assumed that they all contribute to all kind of valences. That is to say, that a higher level of task-specific autonomy, feasibility, relatedness and subjective norm can influence task-specific motivation, because they can affect the level of affective and cognitive, positive and negative valences. It is important to emphasize that the model is limited to task-specific aspects of these antecedents. The UMTM focuses, for instance, on the autonomy one has in a specific activity, not on the level of autonomy one experiences in general in a certain context. Evidently, that is not to say that the latter is unimportant, but it is assumed that in the end its influence is actualized in a task-specific implementation.

A particular feature in the model is the distinction between the person and his or her context, which leads to a partition of some components in the model. The distinction between personal and non-personal cognitive valences was introduced above already. In addition also autonomy and feasibility are divided in a personal and a contextual facet. The personal facet of autonomy is labelled sense of personal autonomy and is defined as the extent to which the person experiences himself or herself as the originating force that drives performance of an activity. The distinction here is whether the self feels driving or driven. The contextual part of autonomy is labelled perceived freedom of action and entails the liberty a person perceives in the action context to decide independently about choice and execution of action alternatives (cf. Reeve, Nix, \& Hamm, 2003). Of course, both aspects are related. Their fundamental distinctiveness, however, is disclosed by the possibility that one can still experience the self as the driving force in a situation where one has no freedom of action. That possibility is also the reason why it is assumed that sense of personal autonomy is the shaping 
factor and that in a specific context perceived freedom of action is important to the extent it contributes to sense of personal autonomy. Notice again that we are dealing here only with task-specific factors. The role of a more general freedom of action (for instance at the level of the school in general) might very well be different. Furthermore, it was speculated that sense of personal autonomy is differently related to different types of valences. Sense of personal autonomy affects cognitive valences, but sense of personal autonomy and affective valence are presumably reciprocally related. If I experience myself as origin of my actions, it is very likely that I also experience pleasure during performance, and the other way around: if I experience pleasure performing an activity, it is very likely that I have a feeling of personal autonomy. In concrete situations sense of personal autonomy and affective valence act like communicating vessels.

Feasibility has also two sides. The personal side of feasibility is sense of personal competence and refers to the estimate of personal capacities, knowledge and skills that are available to complete an activity at an acceptable level of performance. The contextual part, an estimate of circumstances that hinder or support performance of a specific activity, is called perceived external support (de Brabander, Rozendaal, \& Martens, 2009; Imants \& de Brabander, 1996; Smit, de Brabander, \& Martens, 2014). Both are needed for successful performance, which is why a feasibility appraisal was conceived as the result of both components. It is assumed, however, that sense of personal competence in general will supply the higher contribution of the two, because people can overcome hindrances and obstacles by stepping up their effort, for instance.

Theoretically it would be possible to apply the distinction between person and context also to relatedness, with on one hand the level of relatedness one perceives between the members of an action context in general as the contextual aspect, and on the other the level of relatedness one personally feels with the members of an action context as the personal aspect. However, as long as a distinctive role of the contextual part is unlikely, the model makes only room for the personal part: sense of personal relatedness. There is one more aspect that makes relatedness different from the other conditional factors, not theoretically, but practically. Certainly in educational settings, the group of people that populates the action context is relatively stable across tasks. In practice then, sense of personal relatedness is less task-specific than autonomy and feasibility.

\subsection{Direct or mediated effects}

Different theories also disagree about the paths of influence of different antecedents. The socialcognitive theory posits that efficacy expectations shape outcome expectations, which in turn determine motivation. (Bandura, 1977; 1986; 2001; Schunk \& Pajares, 2010) The theory of planned behaviour, however, claims that perceived behavioural control and subjective norm both directly influence intention formation (Ajzen, 1991). De Brabander \& Martens (2014), introducing their Unified Model of Task-specific Motivation, favoured the mediated option. They found it difficult to understand, for instance, why the sheer expectation of a successful performance by itself would increase readiness for action. It seemed more logical that a higher feasibility would lead to a more positive and a less negative valence appraisal and that this valence appraisal would determine readiness for action. Their first empirical exploration of the model, however, suggested that task-specific antecedents could exert their influence along all kinds of paths, direct and mediated by valences (de Brabander \& Martens, 2018). In that study, however, no data on readiness for action were available and instead reports of actual participation were used as a proxy. They found that in addition to effects that were mediated by valences, task-specific antecedents could also have direct effects on readiness for action. We assume, therefore, that to some extent and in some cases, people may gain readiness for action simply because they feel being the origin of their action, because they see good opportunities for a successful performance, because they experience positive relations to other people in the action context, and/or because they want to abide by normative beliefs about that action of significant people in the action context.

\subsection{Time of appraisal}


Developing their Unified Model of Task-specific Motivation De Brabander and Martens (2014) used a future time perspective. They concentrated on activities in the near future. As a result they defined all components of the model as expectancies. However, this future time perspective was only a methodical aid to ease the development of the model. Appraisal of all components of the model can be made at different points in time, not only in foresight, but also during performance of an activity and in hindsight. Point of time will certainly make a difference. It will be easier to anticipate the consequences of an activity during performance of an activity, because a more precise estimate of its outcomes is possible. Assessment of outcomes after finishing an activity requires no anticipating competence. But in all cases, also in the latter, people will vary in what consequences they perceive and how they value them. It is conceivable that the value of outcomes is revealed to the person even many years after completion of an activity (e.g. high school graduation). Therefore, we adapted in the foregoing the definition of all components of the model, where necessary, to enable different times of appraisal by changing "expectancy" into "appraisal".

\subsection{Research questions}

The current study was one of the very first attempts to acquire empirical support for the Unified Model of Task-specific Motivation. As described above this model aims to identify important constructs that are needed to understand the level of motivation and the factors that contribute to this motivation. However, what level of readiness for action a person reaches and how it is formed depends on the valences that actually play a role and on the specific configuration of task-specific antecedents, which in turn depend among others on the specific task at hand. In the current investigation, therefore, we were not in a position to formulate strict hypotheses, but relied instead on two guiding questions. The first question was to what the extent empirical relations between the measures of the components of the UMTM are in accordance with model expectations. The second question was to what extent different activities require different models as specific instantiations of the general model.

In the current investigation we tested the Unified Model of Task-specific Motivation in the context of motivation for professional learning activities of teachers in primary education. Professional learning activities are seen as an important instrument for the improvement of the quality of education. This belief is shared between the Dutch Ministry of Education, school boards and teachers (Research voor Beleid, 2011).

Although in this paper we did not have an interest in teacher professional development per se, it is a relevant field from the perspective of motivation theory. The reasons for this can be found in three debates with regard to teachers and their professional development. We will briefly discuss debates about the professional identity of teachers, educational leadership, and the design of teacher professional development.

With regard to the professional identity of teachers, Swann, McIntyre, Pell, Hargreaves, and Cunningham (2010) point out that teacher autonomy has become a controversial issue lately. In recent education policies, governments in many countries are seeking to replace traditional notions of professional autonomy among teachers by a modern professional identity based on value added performance, efficiency, accountability, teamwork and the willingness to implement change (Ball, 2003; Hardy \& Lingard, 2008). Against the background of current educational reform, the question is raised whether teachers are to be conceived as real professionals in the technical sense of the word or as executive educational workers; should their professional autonomy in educational matters be trusted or should their performance be more or less scripted and closely monitored (Apple \& Jungck, 1990; Ball, 2003; Ballet \& Kelchtermans, 2009; Clark, Livingstone, \& Smaller, 2012; Gleeson \& Husbands, 2003; Milner, 2013); should their professional development be determined by themselves or should it be structured by governmental educational reform agenda's (Borko, Elliott \& Uchiyama, 2002; Starkey et al., 2009). In 2012, the Dutch Ministry of Education concluded with some satisfaction that teachers' professional development choices reflected its educational reform agenda to a considerable extent (Ministerie van OCW, 2012, pp. 18-20). For teachers in Canada, Clark, Livingstone, and Smaller (2012) have shown that teachers experienced increasing constraints in determining the course of their professional development. Policy-driven, compulsory professional development programs met with fierce criticism among these teachers (Clark, Livingstone, \& Smaller, 2012, p. 93; also Locke, 
Vulliamy, Webb, \& Hill, 2005). A Dutch survey among primary and secondary teachers (Onderwijscoöperatie, 2016) reported that decisions about teacher participation in professional development were made by principals or school boards in $48 \%$ of the cases, in $1 \%$ by the teachers, and in $36 \%$ the decision was made jointly by teachers and school boards or principals.

Closely linked to the issue of teacher professional identity is the debate on educational leadership. Decisions about teacher learning issue from the leadership structures and cultures of schools in which both the discretionary powers of school boards or principals, and the 'professional space' for teacher decisions are shaped (Bakkenes, 1996). Silins, Mulford, and Zarins (2002) have argued that leadership in schools can be organized on several organizational levels. According to them, the presence of leadership at each organizational level, i.e. school board or principal, the school team, and the individual teachers, is an important condition for organizational learning and professional development. The literature about distributed and teacher leadership takes the team level of leadership as its focal point (Devos, Tuytens \& Hulpia, 2013; Hulpia, Devos \& van Keer, 2011). The assumption here is that the impact that teachers have, both individually and collectively as a team on school decisions will have a beneficial influence on their commitment to school improvement and to professional development. Hargreaves and Dawe (1990) made an important proviso to such expectations. They made a distinction between teacher collaborative cultures where teacher define their own professional development and innovation goals as a community, and 'contrived collegiality' where teacher collaboration is administratively enforced in the context of learning to implement skills and programs developed elsewhere.

A third debate concerns the design of teachers' professional development. Little (1993, p.142) refers to a dominant training and guidance model of professional development of teachers with "packaged knowledge and standardized programs' (cf. Hardy, 2010). They are provided by a market for formal training programs and bought off the shelf by schools accountable for their investment in professional development to school boards and inspectorates. In these programs, teachers are positioned as more or less passive consumers. Little (1993) states that the fit of these programs with learning needs of teachers is often problematic. She goes on to describe alternatives to the standardized professional development format: teacher and school collaboratives and partnerships, which give central importance to teaching contexts and teacher experiences (Penuel, Fishman, Yamaguchi, and Gallagher, 2007). These alternative programs demand active and collaborative construction of knowledge from teachers.

From these three debates, we derived a dimension that relates to teacher autonomy in the sense that it identifies the source of decision-making on participation in professional learning activities. Principals or school boards as decision makers impact the professional autonomy of teachers directly since they imply as a rule mandatory participation for the teachers. Penuel, Fishman, Yamaguchi, and Gallagher (2007) have pointed out that this will in many cases result in incoherence between professional development programs and individual and situation dependent learning goals of teachers. Individual teachers as decision makers will tend to reinforce the notion of professional autonomy among teachers, and may imply better chances of coherence between professional development and individual and situational learning needs, although they may also bring a risk of narrowing down the scope of learning (Little, 1993). Teams as decision makers about teachers' professional development, the intermediate level of decision making between school board and individual decisions, may involve different levels of collective professional autonomy, dependent upon whether they are instances of teacher collaborative cultures or issue from 'contrived collegiality'.

Hence, in our research we discern three sources of decision-making. The decision to take part in professional learning activities can be taken by the school board or the principal, the team of teachers, or the teacher personally.

To sum up, when teachers are confronted with three possible professional learning activities, differing in how they were decided upon, namely by the school board, the team of teachers, or the teacher personally, (1) to what extent is it possible to model the motivational data on these activities according to the UMTM, and as the UMTM is not a deterministic model but a model in which differences between activities determine the 
relations between different components, (2) do the different activities lead to different models and in what respect?

\section{Method}

\subsection{Sample}

The sample was a convenience sample of 441 teachers from 54 primary schools in The Netherlands, 377 female and 63 male ( 1 missing value). Mean age was 42.17 years $($ S.D. $=12.09)$. The age distribution, however, had two modes, at 28 and 56 years approximately. Mean number of years of experience was 16.92 $(S . D .=11.25)$, again with a bi-modal distribution with modes at 6 and 34 years of experience. Of the 402 teachers who reported their appointment size $($ Mean $=30.42$ hours, S.D. $=9.22), 121(30 \%)$ had a full-time appointment (40 hours). Relatively more common part-time appointment sizes were 20 hours (10.2\%), 24 hours $(8 \%)$ and 32 hours $(10.4 \%)$.

\subsection{Variables}

All components of the UMTM (except sense of personal relatedness) were translated in a single question with a bipolar seven-point scale (Table 1). Sense of personal relatedness was discarded because to measure it as a task-specific aspect would require the subject to report on the relations with people involved in a specific activity, and who would be involved in that imaginary activity was by definition not known in advance. The items on positive and negative cognitive valences were differentiated into three items according to the recipient of these valences: the actor self ( $\mathrm{p}$-pcv respectively p-ncv), the students ( $\mathrm{p}-\mathrm{pcv}$ respectively s$\mathrm{ncv}$ ), or the school as an institute (i-pcv respectively i-ncv). This was accomplished by interposing between the two poles three scales that were labelled "for me personally", "for the student", and "for the school". A short explanation of their meaning preceded the items on affective and cognitive valences.

This set of questions was administered three times, once for each of the three professional learning activities. Teachers were asked how they would appreciate these imaginary activities. Each activity was described as a professional learning activity aimed at improving a specific instructional problem, which would take place in the very near future. Activities differed in how they were decided upon. The first activity was framed as a local school board decision, the second as a team decision, and the third as a personal decision. The three activities were introduced as follows:

- "Based on its accountability program, the school board decided to focus on improvement of technical reading and reading comprehension. The board has recruited a third party to organize a course for all teachers of the schools for which it is responsible. Your school received an announcement that the next seminar will be on technical reading and reading comprehension."

- "After careful consultation the teachers assembly determined a number of professional development priorities. The topic of the forthcoming seminar will be one of these priorities: performance-oriented practice."

- "Year after year you noticed that some students have great difficulty to master fraction calculus. You want to participate in a seminar about a new approach that promises to offer a better support for these students. Your school provides the budget you need to follow this course."

\subsection{Analysis}

The relations between the components of our theoretical model were analysed with structural equation modelling. In line with our research questions we used an analysis process that is called 'model generation' 
(Kline, 2011, p. 8). Model generation involves alteration of an initial theoretical model, in our case derived from the UMTM, based on residual covariances, Lagrange Multiplier test, and Wald tests until a model is found that theoretically makes sense, is reasonably parsimonious, and has an acceptably close correspondence to the data. Kline also notes that this probably is the most common type of use of structural equation modeling. But, more importantly, it fitted our theoretical purpose better than a strict confirmatory approach, because we expected the three types of activities to be different specific instances of a general model. What level of readiness for action a person eventually reaches depends very much on the valences that actually play a role and on the specific configuration of task-specific antecedents, which in turn both depend on the specific task at hand. The UMTM implies a distinction between direct and mediated effects. To determine their existence we relied on the so-called test of joint significance, which is superior to using bias-corrected bootstrapping and at the same time far more efficient (Leth-Steensen \& Gallito, 2016). This test means that a mediation effect simply is significant when all paths contributing to the mediated effect are significant.

Developing different models for different tasks would eventually lead to models in which constructs were represented by single items. We did not choose to employ multiple items for each construct to spare teachers the task of completing a lengthy questionnaire that would have to be administered three times anyway. Obviously, with single item measures reliability cannot be determined, but reliability is implied by systematic covariation with other measures. A second problem of single item measures relates to the measurement level. Technically, a seven points scale provides data on an ordered categorical level. However, using 5 categories or more approximate continuous data and using robust maximum likelihood estimation, which we already needed because many of our variables did not satisfy normality assumptions, further reduces the bias level (Finney \& DiStefano, 2013). All analyses were implemented with EQS (Bentler, 2008). 
Table 1

Item formulations for task-specific components

\begin{tabular}{|c|c|c|c|}
\hline \multirow{2}{*}{$\begin{array}{l}\text { sense of personal } \\
\text { autonomy (spa) }\end{array}$} & \multicolumn{3}{|c|}{ I would have the feeling that I participated in such an activity } \\
\hline & only because I had to & - & only because I myself wanted to. \\
\hline \multirow{3}{*}{$\begin{array}{l}\text { perceived freedom of } \\
\text { action }(\mathrm{pfa})\end{array}$} & \multicolumn{3}{|l|}{ Such an activity would offer } \\
\hline & very much & - & very little \\
\hline & & & ... opportunities for free choice. \\
\hline \multirow{3}{*}{$\begin{array}{l}\text { perceived external } \\
\text { support (pes) }\end{array}$} & \multicolumn{3}{|c|}{ I find the facilities and circumstances in our school ... } \\
\hline & very frustrating & - & very conducive \\
\hline & & & $\begin{array}{l}\text {... to completing such an } \\
\text { activity successfully. }\end{array}$ \\
\hline \multirow{3}{*}{$\begin{array}{l}\text { sense of personal } \\
\text { competence }(\mathrm{spc})\end{array}$} & \multicolumn{3}{|l|}{ I myself feel ... } \\
\hline & very competent & - & not competent at all \\
\hline & & & $\begin{array}{r}\text {... to complete such an activity } \\
\text { successfully. }\end{array}$ \\
\hline \multirow[t]{2}{*}{ subjective norm (snc) } & \multicolumn{3}{|c|}{$\begin{array}{l}\text { I think that colleagues whom I feel connected to, would assess my } \\
\text { participation in such an activity ... }\end{array}$} \\
\hline & not positively & - & very positively. \\
\hline \multirow{3}{*}{$\begin{array}{l}\text { positive affective } \\
\text { valences (pav) }\end{array}$} & \multicolumn{3}{|c|}{ During preparation and execution of such an activity I would have ... } \\
\hline & very often & - & seldom or never \\
\hline & & & ... a positive feeling. \\
\hline \multirow{3}{*}{$\begin{array}{l}\text { negative affective } \\
\text { valences (nav) }\end{array}$} & \multicolumn{3}{|c|}{ During preparation and execution of such an activity I would have ... } \\
\hline & seldom or never & - & very often \\
\hline & & & ... a negative feeling. \\
\hline \multirow{2}{*}{$\begin{array}{l}\text { positive cognitive } \\
\text { valences (p-pcv, s- } \\
\text { pcv, i-pcv) }\end{array}$} & \multicolumn{3}{|c|}{ Considering the positive consequences, such an activity would be ... } \\
\hline & not or barely profitable & - & very profitable. \\
\hline \multirow{2}{*}{$\begin{array}{l}\text { negative cognitive } \\
\text { valences (p-ncv, s- } \\
\text { ncv, i-ncv) }\end{array}$} & \multicolumn{3}{|c|}{$\begin{array}{l}\text { To my estimate the costs and any unwanted consequences would be } \\
\text {... }\end{array}$} \\
\hline & very consequential & - & negligible. \\
\hline \multirow[t]{3}{*}{$\begin{array}{l}\text { readiness for action } \\
\text { (rfa) }\end{array}$} & \multicolumn{3}{|c|}{$\begin{array}{l}\text { If such an activity was about to take place, I would be willing to } \\
\text { invest ... }\end{array}$} \\
\hline & very little & - & very much \\
\hline & & & \\
\hline
\end{tabular}


Table 2

Distribution characteristics of task-specific components

\begin{tabular}{|c|c|c|c|c|c|c|c|}
\hline \multirow[b]{3}{*}{ board activity } & \multirow[t]{2}{*}{$\mathrm{N}$} & \multirow[t]{2}{*}{ Mean } & \multirow[t]{2}{*}{ SD } & \multicolumn{2}{|c|}{ Skewness } & \multicolumn{2}{|c|}{ Kurtosis } \\
\hline & & & & Value & Std. Error & Value & Std. Error \\
\hline & & & & & & & \\
\hline spa & 438 & 3.84 & 1.423 & .059 & .117 & -.586 & .233 \\
\hline pfa & 436 & 3.36 & 1.296 & .102 & .117 & -.532 & .233 \\
\hline pes & 436 & 4.97 & 1.187 & -.556 & .117 & .150 & .233 \\
\hline spc & 437 & 5.51 & 1.304 & -1.260 & .117 & 1.442 & .233 \\
\hline snc & 437 & 4.35 & 1.340 & -.344 & .117 & -.344 & .233 \\
\hline pav & 439 & 4.89 & 1.100 & -.490 & .117 & -.035 & .233 \\
\hline nav & 439 & 3.33 & 1.238 & .252 & .117 & -.702 & .233 \\
\hline$p-p c v$ & 438 & 5.23 & 1.112 & -.982 & .117 & 1.293 & .233 \\
\hline s-pcv & 437 & 5.34 & 1.130 & -1.059 & .117 & 1.402 & .233 \\
\hline i-pcv & 437 & 5.36 & 1.076 & -.952 & .117 & 1.186 & .233 \\
\hline p-ncv & 438 & 3.59 & 1.459 & .201 & .117 & -.784 & .233 \\
\hline s-ncv & 436 & 3.00 & 1.477 & .464 & .117 & -.596 & .233 \\
\hline i-ncv & 433 & 3.51 & 1.386 & .191 & .117 & -.688 & .234 \\
\hline $\begin{array}{l}\text { rfa } \\
\text { team a }\end{array}$ & 435 & 4.90 & 1.162 & -.814 & .117 & .666 & .234 \\
\hline spa & 440 & 4.65 & 1.339 & -.453 & .116 & -.310 & .232 \\
\hline pfa & 439 & 4.18 & 1.430 & -.168 & .117 & -.728 & .233 \\
\hline pes & 441 & 5.06 & 1.187 & -.639 & .116 & .117 & .232 \\
\hline spc & 441 & 5.41 & 1.431 & -1.125 & .116 & .563 & .232 \\
\hline snc & 437 & 4.90 & 1.223 & -.625 & .117 & -.016 & .233 \\
\hline pav & 439 & 5.02 & 1.222 & -.859 & .117 & .289 & .233 \\
\hline nav & 439 & 3.01 & 1.194 & .776 & .117 & .295 & .233 \\
\hline p-pcv & 440 & 5.42 & 1.066 & -1.083 & .116 & 1.831 & .232 \\
\hline s-pcv & 441 & 5.54 & 1.002 & -.845 & .116 & 1.538 & .232 \\
\hline i-pcv & 441 & 5.58 & .990 & -1.001 & .116 & 2.094 & .232 \\
\hline p-ncv & 437 & 3.32 & 1.426 & .457 & .117 & -.556 & .233 \\
\hline S-ncv & 436 & 2.84 & 1.409 & .639 & .117 & -.377 & .233 \\
\hline i-ncv & 436 & 3.22 & 1.349 & .438 & .117 & -.558 & .233 \\
\hline rfa & 435 & 5.19 & 1.148 & -1.063 & .117 & 1.582 & .234 \\
\hline person & & & & & & & \\
\hline spa & 440 & 6.24 & 1.030 & -2.020 & .116 & 5.600 & .232 \\
\hline pfa & 437 & 5.11 & 1.737 & -.696 & .117 & -.639 & .233 \\
\hline pes & 439 & 5.22 & 1.331 & -.773 & .117 & .079 & .233 \\
\hline $\mathrm{spc}$ & 439 & 5.90 & 1.317 & -1.888 & .117 & 3.522 & .233 \\
\hline snc & 437 & 5.30 & 1.366 & -.971 & .117 & .333 & .233 \\
\hline pav & 438 & 5.70 & 1.312 & -1.549 & .117 & 2.426 & .233 \\
\hline nav & 438 & 2.48 & 1.335 & 1.316 & .117 & 1.356 & .233 \\
\hline p-pcv & 438 & 6.10 & .983 & -1.412 & .117 & 2.652 & .233 \\
\hline s-pcv & 436 & 5.92 & .934 & -1.171 & .117 & 2.199 & .233 \\
\hline i-pcv & 438 & 5.69 & 1.022 & -1.051 & .117 & 1.938 & .233 \\
\hline p-ncv & 439 & 2.77 & 1.471 & .895 & .117 & .094 & .233 \\
\hline s-ncv & 438 & 2.52 & 1.391 & .973 & .117 & .444 & .233 \\
\hline i-ncv & 436 & 2.89 & 1.378 & .647 & .117 & -.207 & .233 \\
\hline $\mathrm{rfa}$ & 439 & 5.89 & 1.056 & -1.271 & .117 & 2.082 & .233 \\
\hline
\end{tabular}




\section{Results}

\subsection{Descriptive statistics}

In Table 2 the distribution characteristics of the task-specific components were collected (cf. also Table 1). Higher scores represent a higher level of the variable involved.
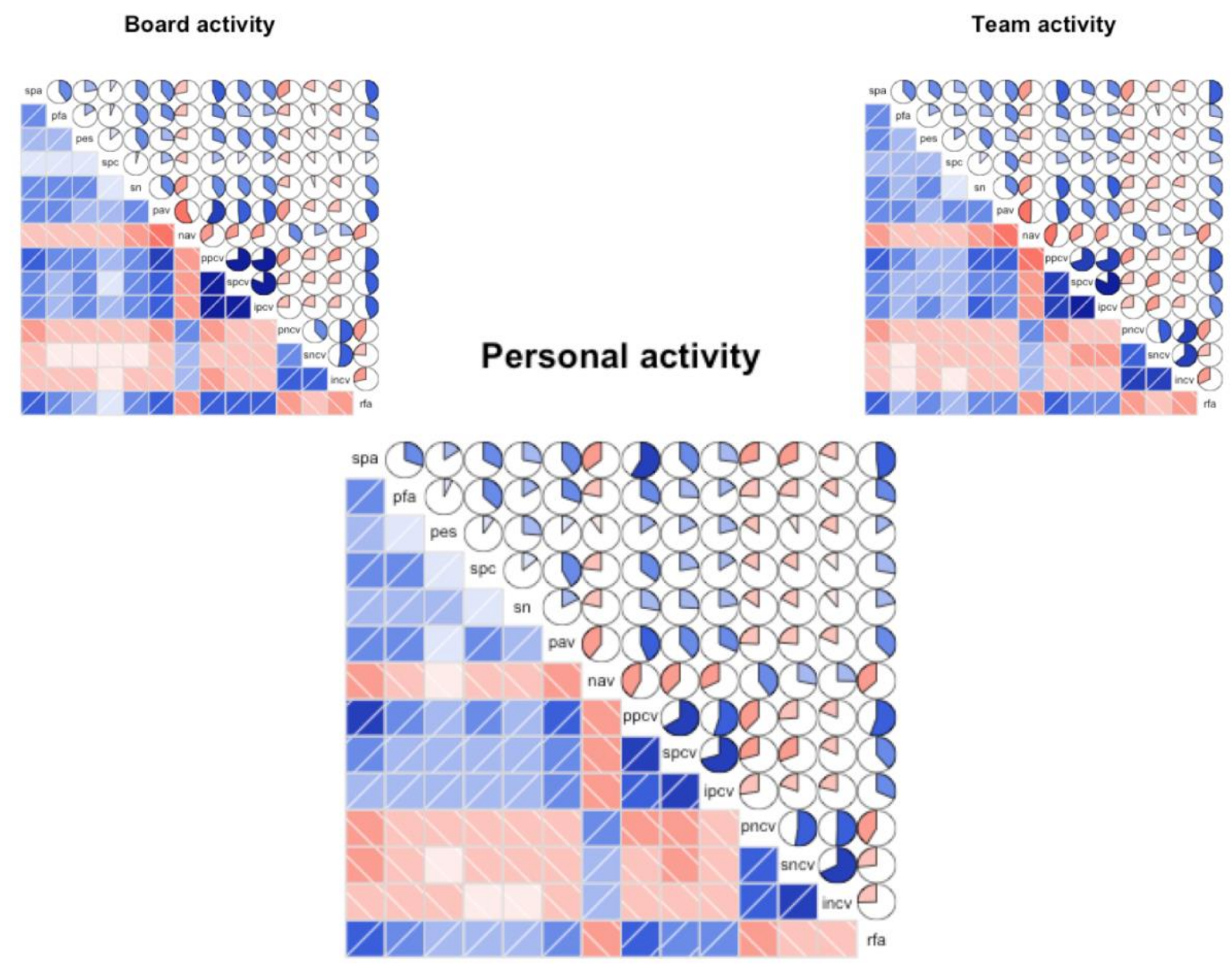

Figure 2. Correlograms of task-specific components in three activities. Legend: Color shades and pie charts indicate the correlation level. Blue shades and clockwise pie charts represent positive correlations, red shades and counter-clockwise pie charts represent negative correlations. 


\subsection{Differences between activities}

The distribution characteristics of the task-specific components (Table 2) revealed already some differences between the three professional learning activities. And although the pattern of correlations between task-specific components showed a substantial agreement (Figure 2), the fit of a confirmatory factor analysis model with 14 factors under the assumption that there are essentially no differences between activities, was highly unacceptable: $\chi^{2}(N=396)=3446.529, d f=728, \mathrm{CFI}=.605, \mathrm{NNFI}=.533$, RMSEA $=.097-90 \%$ CI: $.094-.100$. From this analysis we concluded that it was indeed necessary to develop a separate model for each activity. We were not able, however, to corroborate this conclusion with a multitrait-multimeasure model in which each task-specific component was allowed to load both on a task-specific component and on an activity: the estimation phase took 332 iterations to alleviate non-positive definiteness and another 396 iterations to reach convergence and still produced illogical parameter estimates.

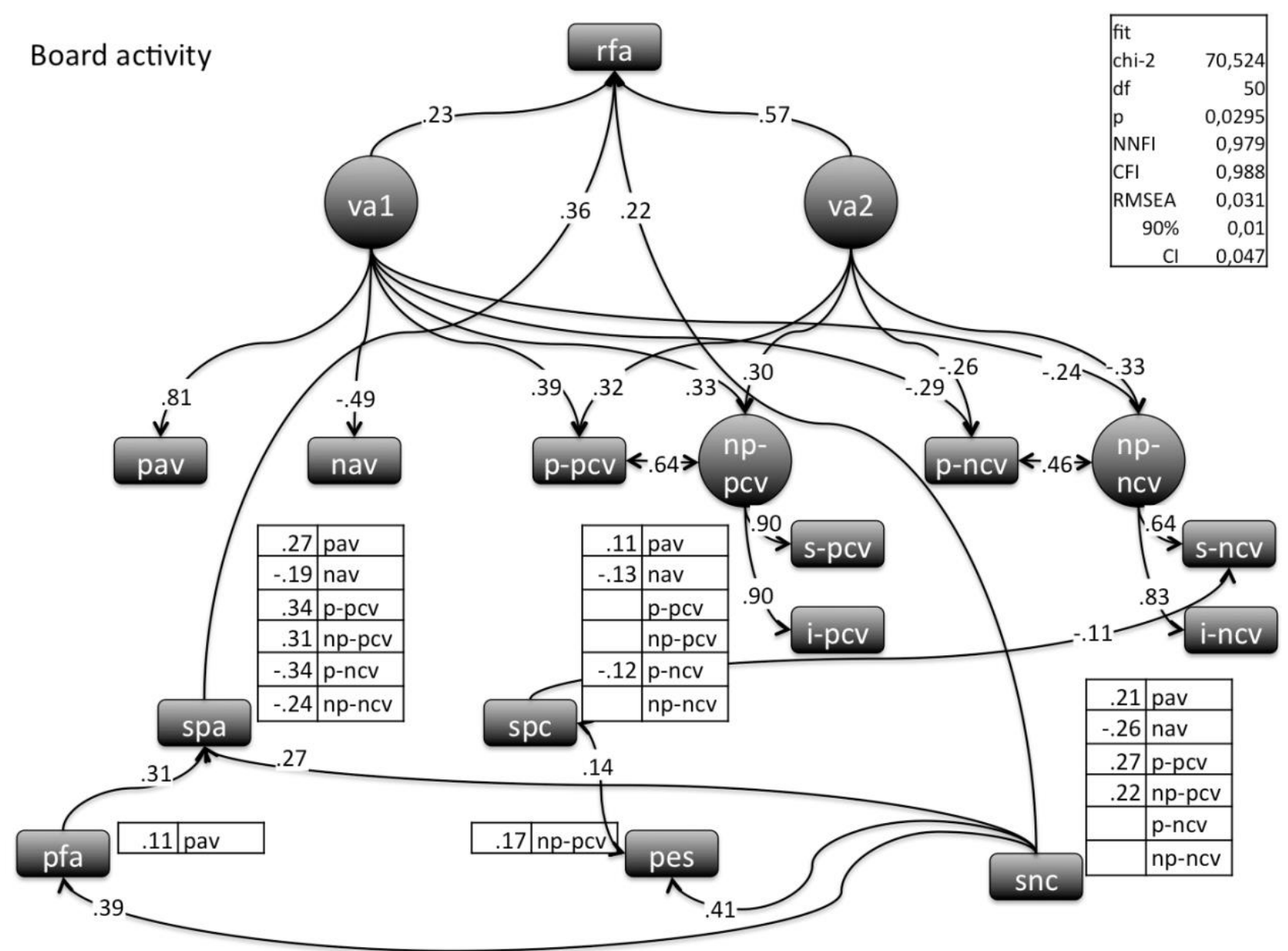

Figure 3. Structural regression model of the task-specific components for the board decided professional development activity.

Thus, each professional development activity was analysed separately. Therefore, the majority of components in the model was measured by one item, and consequently was represented by manifest variables. In each case we started with the relations as suggested by the UMTM. The endogenous variable in this model was readiness for action (rfa). According to the UMTM, readiness for action is influenced by a valence appraisal (va). As we did not have direct measurements of this valence appraisal, we modelled the covariance between valences and readiness for action as a latent variable with valences as indicators. However in each type of activity it proved to be possible to combine cognitive valences for the school (institute, i-pcv and i$\mathrm{ncv}$ ) and for the student (s-pcv and s-ncv) in two latent variables: non-personal positive cognitive valences (np-pcv) and non-personal negative cognitive valences (np-ncv). Thus six types of valences were combined in 
a latent factor: positive and negative affective valences (pav and nav), personal positive cognitive valences (p$\mathrm{pcv}$ ), non-personal positive cognitive valences (np-pcv), personal negative cognitive valences (p-ncv), and non-personal negative cognitive valences (np-ncv). We hypothesized that these six types of valences, in turn, were influenced by task-specific antecedents. Sense of personal autonomy influenced all valences and was influenced by perceived freedom of action (pfa). In the UMTM sense of personal competence (spc) and perceived external support (pes) combine into a feasibility appraisal, however, based on their low correlation in our dataset and considering that we had no direct measurement of feasibility appraisal, we treated them as separate components. The last task-specific antecedent that was expected to influence valences was subjective norm of colleagues (snc). In each analysis, we removed or added paths based on residual covariances, Lagrange Multiplier tests and Wald tests to attain three models as specialized instances of the general model. Thus we arrived at the three models that are pictured in Figure 3, 4, and 5. To ease the readability of these figures, the multitude of paths between task-specific antecedents and the different valences was presented in embedded tables. The fit measures of all three models were satisfactory and are reported in the Figures. The results of these analyses are presented under three headings: the influence of valences on readiness for action, the influence of task-specific antecedents on valences, and the direct influence of task-specific antecedents on readiness for action. The correlated error terms that were left free for estimation in order to improve model fit are reproduced in the Figures.

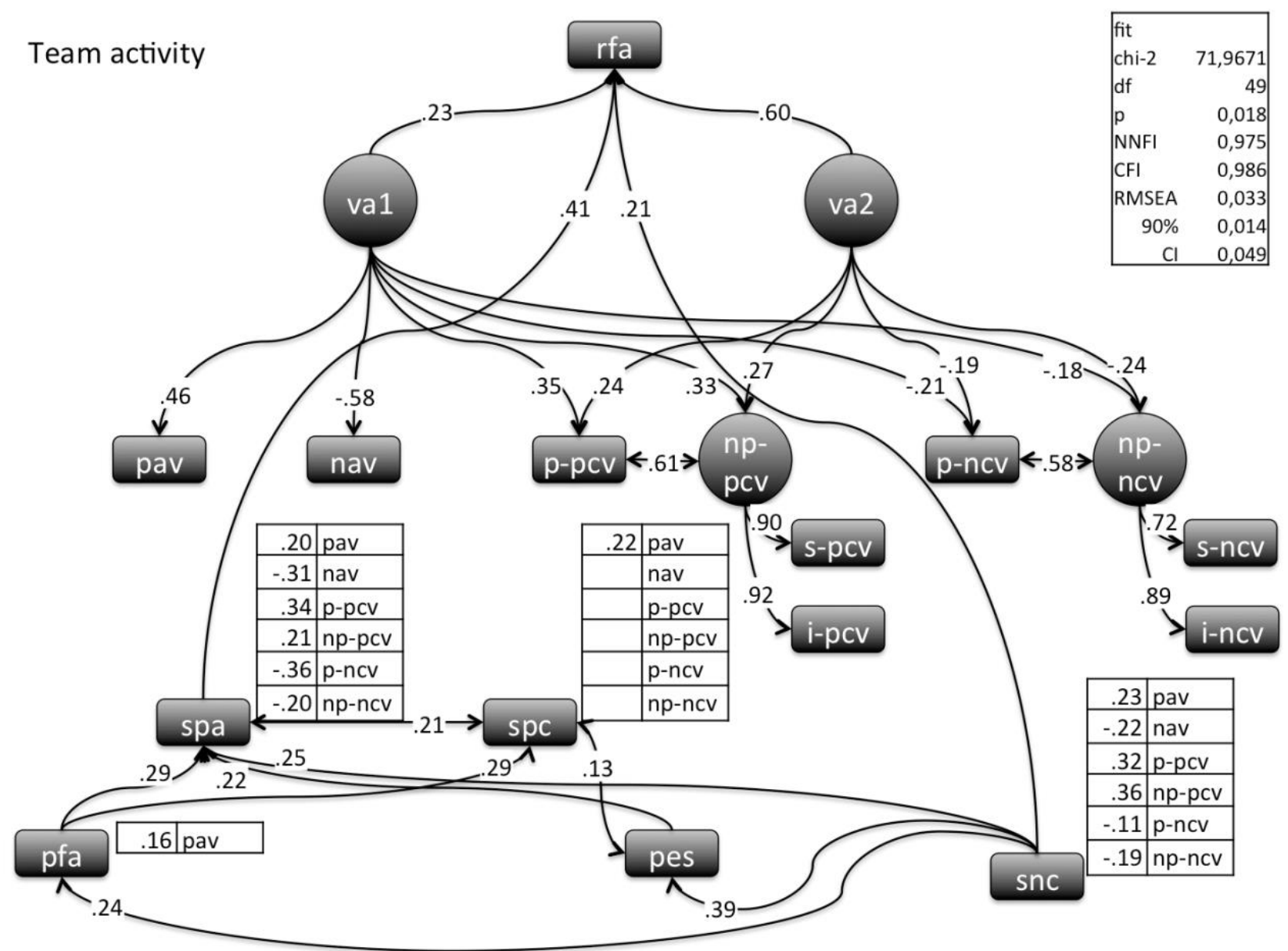

Figure 4. Structural regression model of the task-specific components for the team decided professional development activity. 


\subsection{Influence of valences on readiness for action}

For two activities, the board activity and the personal activity, one valence appraisal factor was not enough to capture the covariance between valences and readiness for action (rfa) sufficiently. To account for residual covariances between valences and readiness for action we had to assume a second valence appraisal factor. In the model for the team activity, however, it was possible to develop a model with one valence appraisal factor with a more or less equal fit compared to a model with two valence appraisal factors. We chose the latter based on its comparability to the other two and its interpretability. Though this part of all three models had thus the same components, the path coefficients were quite different. In the model for the board activity the first valence appraisal factor (va1) pav had the highest loading, followed by nav with a negative loading. The positive cognitive valence components had smaller loadings and negative cognitive valence components had the smallest loadings on va1. In the second valence appraisal factor (va2) only cognitive valences were combined with loadings that are more or less of the same level as the loadings on va1. However, the path coefficient of va2 to rfa (.57) was substantially higher that the path coefficient of va1 to rfa (.23). This was also the case in the model for the team activity (.60 vs .23). However, the loading of pav on val was much lower. Here, the negative loading of nav was the highest, and the loadings of cognitive valences on val were at the same (smaller) level. Again for this activity, the loadings of cognitive valences on va2 were very modest. In the model for the personal activity the path coefficients were very different. Differences in loadings on va1 between affective and cognitive valences were smaller and all loadings were rather substantial. And here, only the personal cognitive valences had loadings on va2 and they were relatively small. Furthermore, the path coefficients of va1 and va2 to rfa were equal. 


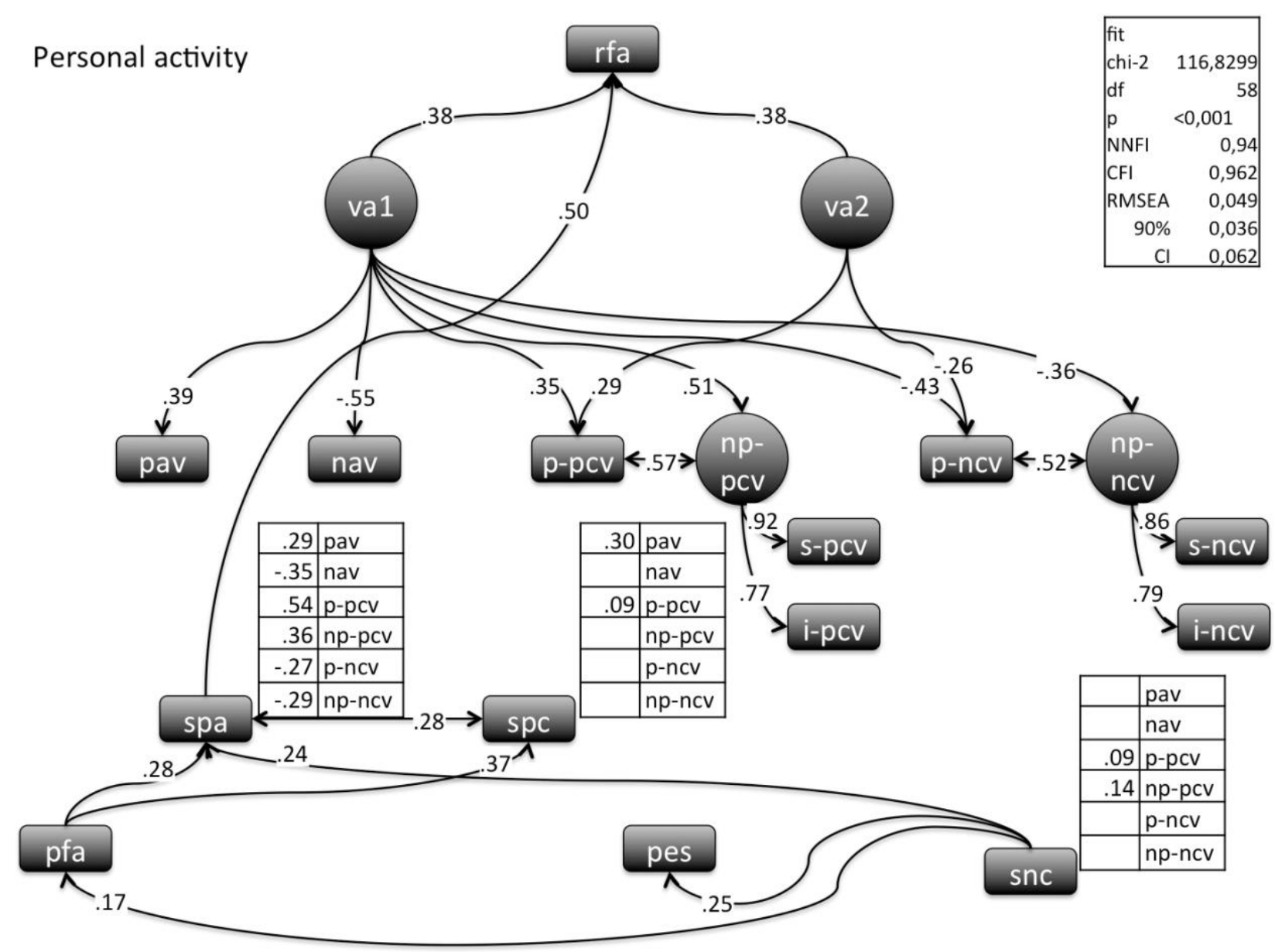

Figure 5. Structural regression model of the task-specific components for the personally decided professional development activity.

\subsection{Influence of task-specific antecedents on valences}

Sense of personal autonomy (spa) influenced all valences in all activities with a relatively high path coefficient on personal positive cognitive valence (p-pcv). Rather surprisingly there were hardly any influences of sense of personal competence (spc) on valences in the three activities. Subjective norm of colleagues (snc) had influence on four valence components in the board activity, on all six in the team activity, but only on two in the personal activity, namely the positive cognitive valences, and both at a hardly meaningful level.

Perceived freedom of action (pfa) contributed to spa in all activities. In the team activity and the personal activity pfa contributed also to spc. Furthermore, in the board activity and the team activity pfa had also a small influence on pav. In none of the activities perceived external support (pes) influenced any of the valences. In all three activities snc influenced pfa, pes and spa.

\subsection{Direct influence of task-specific antecedents on readiness for action}

All activities revealed a substantial direct effect of spa on rfa, especially in the personal activity. There was in none of the activities a direct effect of spc on rfa. Snc showed a modest direct contribution to rfa in the board and the team activity, but not in the personal activity. 


\section{Discussion}

The results of our analyses showed that cognitive valences dominated readiness for action in the board decided and the team decided activity, but that the influence of affective and cognitive valences was more balanced in the personally decided activity. In the latter case the first valence appraisal factor was a balanced combination of affective and cognitive valences, whether positive or negative; a small part of the valences, namely the personal cognitive valences combined in the second valence appraisal factor. Still these two factors of valences contributed equally to readiness for action. These results imply that in the board decided and the team decided activities readiness for action was predominantly based on the estimated value of the expected consequences of such an activity. In the personally decided activity on the other hand affective and cognitive valences were more balanced and made a stronger contribution to readiness for action, but on top of that, personal cognitive valences made a special and substantial contribution. This means that the feelings that the subjects expected to accompany the personally decided activity, and the estimated values of its consequences contributed equally and substantially to readiness for action, and that the subjects' readiness for action was heightened considerably to the extent they expected valuable outcomes for themselves personally. The board decided activity scored a lower mean value on readiness for action than the team decided activity, that in turn scored lower than the personally decided activity, but all mean values were relatively high.

With respect to the task-specific antecedents of valences, the picture was less clear. Only sense of personal autonomy had a clear influence on all types of valences: a higher sense of personal autonomy led to more positive and less negative valences. The influence of perceived freedom of action was largely mediated by sense of personal autonomy, though, except in the personally decided activity, there was a small contribution to positive affective valences: perceiving more freedom of action slightly raised expectations of positive feelings during these activities.

Sense of personal competence, however, did barely influence the valences. And its pattern of influences was rather incomprehensible. Only in the case of positive affective valences we might discern a pattern: the influence of sense of personal competence was lowest in the board decided activity, somewhat higher in the team decided activity and rose to a meaningful level in the personally decided activity. If we could order the activities according to ownership, the board decided activity would be on the low end and the personally decided activity on the high end. Thus a bold guess would be that sense of personal competence mattered to the level of positive feelings the teacher expected to the extent he or she felt 'owner' of an activity. However, the results of this study on the relation between valences and feasibility as an immediate task-specific antecedent did not support the UMTM. In all theories of motivation competence plays an important role in motivation and that role is well established by research. Maybe the skewedness of the scores on sense of personal competence posed a limit on its relations with other variables, but this cannot be the full explanation: for instance, its skewedness was highest in the personally decided activity, where the relation with positive affective valence was also highest.

Perceived external support played a very minor role in the board and team decided activity. Possibly, the proposed activities were simply too imaginary to allow an estimate of the influence of perceived external support on their expected performance. Perceived freedom of action, however, meaningfully influenced sense of personal competence in the team decided and the personally decided activity: if I am not free to decide, I can't do it.

Subjective norm had its widest influence on valences in the team decided activity. The board decided activity came second and its role in the personally decided activity was hardly worth mentioning. Furthermore, in all three activities subjective norm contributed positively to perceived freedom of action, sense of personal autonomy, and perceived external support.

In all activities, we witnessed also some direct influences on readiness for action from the task-specific antecedents. Most notably sense of personal autonomy contributed to readiness for action in all three activities, in the board decided activity, slightly higher in the team decided activity and highest in the personally decided activity. Subjective norm showed also some direct effects, but only in the board and the team decided activities. 
All in all we concluded that the differentiation in different types of valences, which is a hallmark of the UMTM, was strongly supported by the different configuration of valences that we found in different activities. Each activity provoked a different set of affective and cognitive, and positive and negative valences that carried different weights for the resulting readiness for action. The path coefficients of the valences in different activities aptly demonstrated the intricate interaction between different types of valences.

With respect to the relation between task-specific antecedents and valences we needed a more balanced account. Sense of personal autonomy influenced all valences as expected. However, sense of personal competence largely failed to influence valences: sense of personal competence was relevant in some cases to some valences and generally at a very low level. A possible explanation could be the imaginary character of the activities. What exactly would be the requirements of the proposed activities possibly was not clear yet. On the other hand, these activities were not uncommon, so that competence expectations could have been taken from experience. Subjective norm was relevant to the valences, provided that the activity had a social character, as was the case in the board decided and the team decided activity, but less so in the personally decided activity. De Brabander and Martens (2018) similarly witnessed this conditional role of subjective norm. Taking also its direct influence on readiness for action in two of the three activities into account, we may conclude that subjective norm proved to be an important addition to the UMTM.

Autonomy appears to be a special factor in the way teachers frame their professional live. Sense of personal autonomy influenced all valences in every activity. And in all activities, though in somewhat varying degrees, there was a direct effect of sense of personal autonomy on readiness for action. Furthermore, perceived freedom of action was related to sense of personal competence in the two activities, where the teacher was not completely free.

Originally (de Brabander \& Martens, 2014) the assumption prevailed that the influence of task-specific antecedents is mediated by valences. Thus, subjective norm, for instance, would affect readiness for action because, when everybody involved supports an activity, doing that activity would be more pleasurable and would lead to more and better outcomes. The current study and the study by De Brabander \& Martens (2018) leave no other option than to revise this position. The direct effects of task-specific components on readiness for action (in Figure 1 represented by dashed lines) have to be acknowledged as real possibilities. And these possibilities have to be extended to include also autonomy. Sense of personal autonomy has a direct effect on readiness for action. The high strength of this effect could have been the consequence of the type of framing we used in this study: the locus of decision-making.

An open question remains how to interpret these direct effects. The easiest case may be subjective norm. When important colleagues are in favour of an activity, that alone may be enough to make one willing to adopt that activity: people need not bother to consider any consequences or to pay attention to whether it is pleasurable or not; they are willing to get into that activity, because they are inclined to live up to expectations of valued colleagues. It becomes more difficult to imagine what happens when feasibility directly influences readiness for action. We did not find such an effect in this study, but it was found by de Brabander \& Martens (2018). Such an effect would involve doing an activity simply because you can do it. It might be the case, however, that valences are taken more for granted to the extent one feels competent at a certain activity. The case that is most difficult to understand is represented by the direct effect of sense of personal autonomy: doing an activity for the sake of being the driving force in that activity. In the current study this effect may have been exaggerated because of the type of framing used, but in other cases (de Brabander \& Martens, 2018) this effect was also apparent.

As was stipulated before, this study was one of the first attempts to collect empirical evidence on the UMTM. In these attempts we had no intention to develop sharp hypotheses in order to discriminate between alternative theories. It is nevertheless worthwhile to reflect on the implications of the results of our analyses for the different theories that contributed to the UMTM. An obvious first issue here is the relation between affective and cognitive valences. Self-determination theory assumes an opposition between intrinsic and extrinsic motivation: motivation is optimal when it is intrinsic, but as soon as consequences of an activity play a motivating role, motivation is less optimal. Extrinsic motivation is further differentiated into different types, 
where some types of extrinsic motivation (identification and integration), which together with intrinsic motivation are called autonomous motivation, are less detrimental than other types (external regulation and introjection), which are called controlled motivation (Ryan \& Deci, 2000a; 2000b). The UMTM assumes a conceptual independence both between cognitive and affective, and between positive and negative valences. All structural models in the current study showed that positive cognitive and affective valences were positively related. This was, obviously, not a very surprising outcome as research based on expectancy*value theory consistently found a positive relation between intrinsic value and other types of subjective value (Eccles, Wigfield, Harold, \& Blumenfeld, 1993; Eccles \& Wigfield, 1995; Wigfield \& Cambria, 2010). Our results are no exception in that respect. Once again, we may conclude that the adoption of a universal opposition between intrinsic and extrinsic motivation is not warranted. Additional support for this conclusion comes from impeccable sources, namely meta-analyses of the effect of verbal rewards (Deci, Koestner, \& Ryan, 1999; 2001). If extrinsic versus intrinsic motivation is a one-dimensional contrast, we would expect autonomous types of extrinsic motivation to have a less impeding effect than controlled types of extrinsic motivation. However, these meta-analyses showed that verbal rewards (positive feedback) that are experienced as autonomy supportive (i.e. an autonomous type of extrinsic motivation) actually enhanced motivation substantially, that is, were more motivating than intrinsic motivation on its own (cf. De Brabander \& Martens, 2014). Furthermore, by asking in the current study also about negative valences, we showed that there are always also negative valences that are negatively related to positive valences, implying in the first place that cognitive valences can be opposed to affective valences. Secondly, we found in our results not only signs of possible oppositions between cognitive and affective valences, but also between affective valences and between cognitive valences. An activity does have both consequences that are valued positively and consequences that are valued negatively, which is understandable when we realize that profits come only at the expense of effort, and that activities have multiple consequences, some valued positively and others negatively. Our results showed, furthermore, that activities also may spawn both positive and negative feelings, in different quantities. An activity is an assembly composed of different aspects, some of which may be more or less pleasant and others more or less unpleasant. Thus, this differentiation of conceptually independent positive and negative, and affective and cognitive valences is more plausible than the conception of an opposition of intrinsic and extrinsic motives, irrespective of the further differentiation of the latter. We do regard the oppositional view of intrinsic and extrinsic motivation as a premature coagulation of theoretical thoughts about motivation in the early days of self-determination theory. Confronted with the widespread use of extrinsic rewards, unrelated to the inherent goals of learning activities, and the conspicuous differences with activities apparently based on the joy of performing, self-determination theorists adopted an oppositional view that was generalized to all types of extrinsic motivation. It is about time to revise this view, which we do regard to affect only a minor part of the rich body of knowledge that self-determination theory has to offer, including the valuable distinction between different types of extrinsic motivation.

Expectancy*value theories construe an additive relation between different types of subjective value (de Brabander \& Martens, 2014). The reflection on our results led us to conjecture that not this additivity per se is the key issue - after all the combination of positive and negative, affective and cognitive valences in a resultant valence appraisal also represents some sort of weighted compound - but instead the fact that this additive relation is based on a failure of expectancy*value theories to recognize the conceptual difference between affect and cognition. In the expectancy*value theory of achievement motivation (Wigfield \& Eccles, 2000) intrinsic value, attainment value, and utility value are seen as different types of subjective value, which gives them implicitly a certain level of empirical independence: for instance, for some people behavioural choices might be determined more by intrinsic value, whereas for others attainment value might be more important. But fundamentally, all values belong to the same category of subjective values. And although it is nowhere explicitly defined as such, this would imply that the expectancy*value theory of achievement motivation views intrinsic value actually as a cognitive appraisal of the pleasure that is connected to a specific activity. That is a different view than the conceptualization of affective valences, which, to play their role in behavioural regulation, may, but need not be conscious. The theory of planned behaviour is not explicit about the differences between affect and cognition, but in one study on leisure activities Ajzen (1991, p. 200) refers to empirical differences between "affective" and "evaluative" judgments of activities. However, despite their 
convergent and discriminant validity, the distinction was not judged relevant, let alone conceptually scrutinized, as it did not improve the prediction of leisure intentions. Our results obviously do not offer any definite arguments for a choice between the UMTM and expectancy*value theories, because the methods we used were comparable. We tried to elicit affective valences by asking our subjects to reflect on the feelings that would accompany different activities, just the same as in studies based on expectancy*value theories. By definition, therefore, we have missed feelings that failed to reach consciousness and were nevertheless influential. This difference between implicit and explicit valences will be an important matter of concern in future research.

The second point for reflection relates to the distinction between approach and avoidance motivation. Both self-determination theory and expectancy*value theories do not examine potential differences between positive and negative motivators. In self-determination theory (Ryan \& Deci, 2000a; 2000b) external regulation, which is one of the four types of extrinsic motivation, involves motivation based on external rewards and punishments. As such it is the only type of motivation that mentions positive and negative incentives explicitly, but without attention for any conceptual difference. Introjection is another type of controlled motivation that is based on approval from self or others. A guileless reader might be inclined to see disapproval as implicitly included in approval, but then again there is no attention for their difference. Other types of extrinsic motivation, identified regulation and integrated regulation, do not provide room for negative incentives. Expectancy*value theories do not distinguish conceptually between positive and negative values. The expectancy*value theory of achievement motivation admittedly defines costs, but as just another type of subjective value (Wigfield \& Eccles, 2000), which subsequently is more or less forgotten as a topic for research (Flake et al., 2015; Wigfield \& Cambria, 2010; for an exception see Battle and Wigfield, 2003). According to the theory of planned behavior consequences can be beneficial or detrimental but their differences are not conceptually designated (Ajzen, 1991). Our study did, obviously, not lead to a sharp verdict on this matter, but the differential role of negative valences in our analyses suggest that a neglect of the conceptual difference between approach and avoidance motivation is not justified. Although the difference between approach and avoidance motivation is convincingly substantiated empirically (Elliot, 2006; Carver, 2006), it is for future research to establish its relevance for the distinction between positive and negative valences in the UMTM.

All results of our studies confirm that the UMTM is not a deterministic model. It is a framework that describes different components that may be important for motivated action in concrete cases. It is a heuristic model that is useful to describe motivation in specific situations. Which components play a role and how important they are depends very much on the specific activity, its specific context and the specific characteristics of the actor. Therefore, we also need many more studies of the UMTM involving a wide variety of activities and of actors to explore the impact of this variation on the relative importance of different components. For instance, we referred above to the conspicuous role of autonomy-related aspects in the UMTM. An interesting question is to what extent these autonomy-related phenomena are typical of the population of teachers. The role of autonomy in our data reminded us of the topic of teacher isolation that received much attention in the past (Bakkenes, 1996; Bakkenes, de Brabander, \& Imants, 1999; Little, 1990; Lortie, 1975). We need many more distinctive examples to be able to separate the peculiarities from the generalities. However, the categorization of valences in the UMTM as either affective or cognitive, and either positive or negative, and the differentiation of cognitive valences in personal and non-personal valences has proven to offer better possibilities for the explanation of motivational phenomena than either a onedimensional opposition between intrinsic and more extrinsic types of motivation or a simple addition of different types of subjective values. 


\section{Keypoints}

- Intrinsic and extrinsic motivation, respectively subjective value are redefined as affective and cognitive valences

Valences can be positive (approach motivation) or negative (avoidance motivation)

- These four types of valences appear to be relatively independent

- The key sources of valences, autonomy, feasibility, relatedness, and subjective norm, are not equally important in all concrete action contexts

In the context of professional development of teachers, autonomy and subjective norm proved affect readiness for action directly

\section{References}

Ajzen, I. (1991). The theory of planned behavior. Organizational and Human Decision Processes, 50, 179211. doi: 10.1016/0749-5978(91)90020-T

Ajzen, I., \& Fishbein, M. (2008). Scaling and testing multiplicative combinations in the expectancy-value model of attitudes. Journal of Applied Social Psychology, 38, 2222-2247. doi: 10.1111/j.15591816.2008.00389.x

Apple, M. W., \& Jungck, S. (1990). "You don't have to be a teacher to teach this unit": Teaching, technology and gender in the classroom. American Educational Research Journal 27, 227-251.

Bakkenes, I. (1996). Professional isolation of primary school teachers; a task-specific approach. Doctoral dissertation. Leiden: DSWO press, Leiden University.

Bakkenes, I., de Brabander, C. J., \& Imants, J. G. M. (1999). Teacher isolation and communication network analysis in primary schools. Educational Administration Quarterly, 35, 166-202. doi: $10.1177 / 00131619921968518$

Ball, S. J. (2003). The teacher's soul and the terrors of performativity. Journal of Education Policy, 18, 215 228. doi: 10.1080/0268093022000043065

Ballet, K., \& Kelchtermans, G. (2008). Workload and willingness to change: Disentangling the experience of intensification. Journal of curriculum studies, 40, 47-67. doi: 10.1080/00220270701516463

Bandura, A. (1977). Self-efficacy: Toward a unifying theory of behavioral change. Psychological Review, 84, 191-215. doi: 10.1037//0033-295X.84.2.191

Bandura, A. (1986). Social foundations of thought and action. Englewood Cliffs, NJ: Prentice-Hall.

Bandura, A. (1992). On rectifying the comparative anatomy of perceived control: Comments on 'Cognates of personal control'. Applied and Preventive Psychology, 1, 121-126. doi: 10.1016/S0962$1849(05) 80153-2$

Bandura, A. (1997). Self-efficacy: The exercise of control. New York: W. H. Freeman \& Co.

Bandura, A. (2001). Social cognitive theory: An agentic perspective. Annual Review of Psychology, 52, 126. doi: 10.1146/annurev.psych.52.1.1

Battle, A., \& Wigfield, A. (2003). College women's value orientations toward family, career, and graduate school. Journal of Vocational Behavior, 62, 56-75. doi:10.1016/S0001-8791(02)00037-4

Bentler, P. M. (2008). EQS 6 Structural Equations Program Manual. Encino, CA: Multivariate Software, Inc. 
Boekaerts, M., Van Nuland, H.J.C., \& Martens, R.L. (2010). Perspectives on motivation: What mechanism energise students' behaviour in the classroom. In K. Littleton, C. Wood, \& J. Kleine Staarman (Eds.), International handbook of psychology in education (pp. 535-568). Bingley, UK: Emerald Group Publishing Limited.

Borko, H., Elliott, R., and Uchiyama, K. (2002). Professional development: a key to Kentucky's educational reform effort. Teaching and Teacher Education, 18, 969-987. doi: 10.1016/S0742-051X(02)00054-9

Carver, C. S. (2006). Approach, avoidance, and the self-regulation of affect and action. Motivation and Emotion, 30, 105-110. doi: 10.1007/s11031-006-9044-7

Clark, R., Livingstone, D. W., \& Smaller, H., Eds. (2012). Teacher learning and power in the knowledge society. Rotterdam, Netherlands: Sense.

Csikszentmihalyi, M. (1990). Flow: The psychology of optimal experience. New York: Harper \& Row.

Deci, E. L., Koestner, R., \& Ryan, R. M. (1999). A meta-analytic review of experiments examining the effects of extrinsic rewards on intrinsic motivation. Psychological Bulletin, 125, 627-668. doi: 10.1037/00332909.125.6.627

Deci, E. L., Koestner, R., \& Ryan, R. M. (2001). Extrinsic rewards and intrinsic motivation in education: Reconsidered once again. Review of Educational Research, 71, 1-27. doi: $10.3102 / 00346543071001001$

Deci, E. L., \& Ryan, R. M. (2000). The "what" and "why" of goal pursuits: Human Needs and the selfdetermination of behaviour. Psychological Inquiry, 11, 227-268. 10.1207/S15327965PLI1104_01

de Brabander, C. J., \& Martens, R. L. (2014). Towards a unified theory of task-specific motivation. Educational Research Review, 11, 27-44. doi: 10.1016/j.edurev.2013.11.001

de Brabander, C. J., \& Martens, R. L. (2018). Empirical exploration of a unified model of task-specific motivation. Psychology, 9, 540-560. doi: 10.4236/psych.2018.94033

de Brabander, C. J., Rozendaal, J. S., \& Martens, R. L. (2009). Investigating efficacy expectancy as criterion for comparison of teacher- versus student-regulated learning in higher education. Learning Environments Research, 12, 191-207. doi: 10.1007/s10984-009-9062-y

Devos, G, Tuytens, M, \& Hulpia, H. (2014). Teachers' organizational commitment: Examining the mediating effects of distributed leadership. The American Journal of Education, 20, 205-231. doi: 10.1086/674370

Eccles, J., \& Wigfield, A. (1995). In the mind of the actor: The structure of adolescents' achievement task values and expectancy-related beliefs. Personality and Social Psychology Bulletin, 21, 215-225. doi: $10.1177 / 0146167295213003$

Eccles, J., Wigfield, A., Harold, R. D., \& Blumenfeld, P. (1993). Age and gender differences in children's self- and task perceptions during elementary school. Child Development, 64, 830-847. doi: $10.2307 / 1131221$

Elliot, A. J. (2006). The hierarchical model of approach-avoidance motivation. Motivation and Emotion, 30, 111-116. doi: 10.1007/s11031-006-9028-7

Elliot, A. J., \& Church, M. A. (1997). A hierarchical model of approach and avoidance achievement motivation. Journal of Personality and Social Psychology, 72, 218-232. doi: 10.1037/00223514.72.1.218

Elliot, A. J., \& Covington, M. V. (2001). Approach and avoidance motivation. Educational Psychology Review, 13, 73-92. doi: 10.1023/A:1009009018235

Epstein, S. (1994). Integration of the cognitive and the psychodynamic unconscious. American Psychologist, 49, 709-724. doi: 10.1037//0003-066X.49.8.709 
Finney, S. J., \& DiStefano, C. (2013). Nonnormal and categorical data in structural equation modeling. In: G. R. Hancock \& R. O. Mueller (Eds.), Structural equation modeling: A second course, $2^{\text {nd }}$ edition (pp. 439-492). Charlotte, NC: Information Age Publishing.

Flake, J. K., Barron, K. E., Hulleman, C., McCoach, B. D., \& Welsh, M. E. (2015). Measuring cost: The forgotten component of expectancy-value theory. Contemporary Educational Psychology, 41, 232-244. doi: 10.1016/j.cedpsych.2015.03.002

Gleeson, D., \& Husbands, C. (2003). Modernizing schooling through performance management: A critical appraisal. Journal of Education Policy, 18, 499-511. doi: 10.1080/0268093032000124866

Hardy, I. (2010) Critiquing teacher professional development: teacher learning within the field of teachers' work. Critical Studies in Education, 51, 71-84. doi: 10.1080/17508480903450232

Hardy, I. \& Lingard, B. (2008). Teacher professional development as an effect of policy and practice: A bourdieuian analysis. Journal of Education Policy, 23, 63-80. doi: 10.1080/02680930701754096

Hargreaves, A, \& Dawe, R. (1990). Paths of professional development: Contrived collegiality, collaborative culture, and the case of peer coaching. Teaching and Teacher Education, 6, 227-241. doi: 10.1016/0742051X(90)90015-W

Hulpia, H, Devos, G, \& Van Keer, H. (2011). The Relation Between School Leadership From a Distributed Perspective and Teachers' Organizational Commitment: Examining the Source of the Leadership Function. Educational Administration Quarterly, 47, 728-771. doi: 10.1177/0013161X11402065

Imants, J. G. M., \& de Brabander, C. J. (1996). Teachers' and principals' sense of efficacy in elementary schools. Teaching and Teacher Education, 12, 179-195. doi: 10.1016/0742-051X(95)00053-M

Kline, R. B. (2011). Principles and practice of structural equation modeling: Third edition. New York: The Guilford Press.

Krapp, A. (2002). Structural and dynamic aspects of interest development: theoretical considerations from an ontogenetic perspective. Learning and Instruction, 12, 383-409. doi: 10.1016/S09594752(01)00011-1

Krapp, A. (2005). Basic needs and the development of interest and intrinsic motivational orientations. Learning and Instruction, 15, 381-395. doi: 10.1016/j.learninstruc.2005.07.007

Leth-Steensen, C., \& Gallitto, E. (2016). Testing Mediation in Structural Equation Modeling: The Effectiveness of the Test of Joint Significance. Educational and Psychological Measurement, 76, 339351. doi: $10.1177 / 0013164415593777$

Little, J. (1990). The persistence of privacy: Autonomy and initiative in teachers' professional relations. Teachers College Record, 91, 509-536.

Little, J. W. (1993). Teachers' professional development in a climate of educational reform. Educational Evaluation and Policy Analysis, 15, 129-151. doi: 10.2307/1164418

Locke, T, Vulliamy, G, Webb, R, \& Hill, M. (2005). Being a 'professional' primary school teacher at the beginning of the 21st century: A comparative analysis of primary teacher professionalism in New Zealand and England. Journal of Education Policy, 20, 555-581. doi: 10.1080/02680930500221784

Lortie, D. (1975). Schoolteacher: A sociological study. Chicago, IL: University of Chicago Press.

Milner, H.R. (2013). Policy reforms and de-professionalization of teaching. Boulder, CO: National Education Policy Center. Retrieved from http://nepc.colorado.edu/publication/policy-reformsdeprofessionalization.

Ministerie van OCW. (2012). Nota Werken in het Onderwijs 2012. [Memorandum Working in the field of education] The Hague, The Netherlands: Ministerie van OCW. 
Onderwijscoöperatie (2016). De staat van de leraar 2016. [The state of the teacher 2016] Retreived from http://www.fvov.nl/wp-content/uploads/2016/04/W-20160413-Staat_van_de_leraar.pdf

Penuel, W. R., Fishman, B. J., Yamaguchi, R., \& Gallagher, L. P. (2007). What makes professional development effective? Strategies that foster curriculum implementation. American Educational Research Journal, 44, 921-958. doi: 10.3102/0002831207308221

Reeve, J., Nix, G., \& Hamm, D. (2003). Testing models of the experience of self-determination in intrinsic motivation and the conundrum of choice. Journal of Educational Psychology, 95, 375-392. doi: 10.1037/0022-0663.95.2.375

Research voor Beleid. (2011). Tussenmeting Convenant Leerkracht 2011 [Intermediate assessment Teacher covenant 2011]. Zoetermeer, The Netherlands: Research voor Beleid.

Ryan, R. M., \& Deci, E. L. (2000a). Self-determination theory and the facilitation of intrinsic motivation, social development, and well-being. The American Psychologist, 55, 68-78. doi: 10.1037/0003066X.55.1.68

Ryan, R. M., \& Deci, E. L. (2000b). Intrinsic and extrinsic motivations: Classic definitions and new directions. Contemporary Educational Psychology, 25, 54-67. doi: 10.1006/ceps.1999.1020

Silins, H. C., Mulford, W. R., \& Zarins, S. (2002). Organizational learning and school change. Educational Administration Quarterly, 38, 613-642. doi: 10.1177/0013161X02239641

Schunk, D. H., \& Pajares, F. (2010). Self-Efficacy Beliefs. In P. Peterson, E. Baker, \& B. McBarry, Eds., International Encyclopedia of Education (Third Edition), pp. 668-672. Oxford: Elsevier. doi: 10.1016/B978-0-08-044894-7.00620-5

Schunk, D. H., Pintrich, P. R., \& Meece, J. L. (2008). Motivation in education. Theory, research, and applications. Upper Saddle River, New Jersey: Pearson Education, Inc.

Smit, K., de Brabander, C. J., \& Martens, R. L. (2014). Student-centred and teacher-centred learning environment in pre-vocational secondary education: Psychological needs, and motivation. Scandinavian Journal of Educational Research, 58, 695-712. doi: 10.1080/00313831.2013.821090

Starkey, L., Yates, A., Meyer, L. H., Hall, C., Taylor, M., Stevens, S., \& Toia, R. (2009). Professional development design: Embedding educational reform in New Zealand. Teaching and Teacher Education, 25, 181-189. doi: 10.1016/j.tate.2008.08.007

Swann, M., McIntyre, D., Pell T., Hargreaves, L. \& Cunningham, M. (2010). Teachers' conceptions of teacher professionalism in England in 2003 and 2006. British Educational Research Journal, 36, 549 571. doi: 10.1080/01411920903018083

Wigfield, A. \& Cambria, J. (2010). Expectancy-value theory: retrospective and prospective. In S. A. Karabenick \& T. C. Urdan, Eds., The Decade Ahead: Theoretical Perspectives on Motivation and Achievement. Advances in motivation and achievement, Volume 16, Part A, pp 35-70. Bingley, UK: Emerald Group Publishing. doi: 10.1108/S0749-7423(2010)000016A005

Wigfield, A., \& Eccles, J. S. (2000). Expectancy-value theory of achievement motivation. Contemporary Educational Psychology, 25, 68-81. doi: 10.1006/ceps.1999.1015 